\title{
EUROPEAN UNION CONSUMERS' VIEWS ON THE PROTECTION OF THEIR PERSONAL DATA: AN EXPLORATORY ASSESSMENT
}

\author{
Călin Vegheşs ${ }^{1}$ \\ Carmen Pantea ${ }^{2}$ \\ Diana Bălan ${ }^{3}$ \\ Bogdan Lalu ${ }^{4}$
}

ABSTRACT: The increasing marketing efforts of the organizations based on the acquiring, processing, storage and employment of the consumers' personal data have imposed the reconsideration, both from the theoretical and practical perspectives, of the concepts describing the privacy, consumer's private space and personalization.

Paper intends to assess, based on secondary data and in an exploratory manner, the views of the consumers from the European Union countries regarding the ways the different organizations present in the market handle their personal data, the degree of awareness associated with the existence and functioning of the personal data protection in their home countries and their perception related to the effectiveness of the personal data protection.

Keywords: privacy, personal data protection, personalization, European Union

JEL codes: M31

\section{Introduction}

Private space of consumers became an extremely important issue to be taken into consideration during the planning and implementation of not only the direct but also of the "traditional" marketing campaigns. The attempts to explain the concept of privacy led to a variety of definitions based on its very diverse related meanings, such as personal information control, reproductive autonomy, access to places and bodies, secrecy, and personal development (Kemp and Moore, 2007). These definitions have tried to clarify the concept of privacy considering the right to be let alone, limited access to the self, secrecy, control of personal information, personhood, and intimacy (Solove, 2002).

Westin has defined privacy (1968) as the claim of individuals, groups or institutions to determine for themselves when, how, and to what extent information about them is communicated to others while Schoeman (1984) adapted the content of privacy at individual level presenting it as a claim, entitlement or right of an individual to determine what information about himself (or herself) may be communicated to others; the measure of control an individual has over information about himself, intimacies of personal identity, or who has sensory access to him; and a state or condition of limited access to a person, information about him, intimacies of personal identity (Jóri, 2007).

Privacy must be seen in connection with the particular area where its content is applied. The above definitions suggest the existence of a consumer's private (or personal) space that can be described using an amount of information about the demographic, psychographic and behavioral characteristics of the individuals (personal data), and the rights the consumer should have, on a

\footnotetext{
${ }^{1}$ Department of Marketing, Faculty of Marketing, Academy of Economic Studies, Bucharest, c_veghes@yahoo.com

${ }^{2}$ UNESCO Chair of Business Administration, Faculty of Business Administration (in Foreign Languages), Academy of Economic Studies, Bucharest, pantea.carmen@gmail.com

${ }^{3}$ Department of Marketing, Faculty of Marketing, Academy of Economic Studies, Bucharest, balan_diana1@yahoo.com

${ }^{4}$ The Gallup Organization Romania, Bucharest, bogdan_lalu@gallup.ro
} 
hand, to disclose or not this information and, on the other hand, to have this information protected through the appropriate laws and means. In the well-developed markets, particularly in the United Kingdom, defining (and defending) the boundaries of the consumer's private space has already reached the point where there is a right of privacy, which has been created, in effect, by the development of the law of confidentiality into a right to prevent the misuse of private information (Grant, 2009).

Protecting the private space of the consumer has become a serious challenge with the overall technological developments and mostly with the growth of the Internet. While privacy expectations and legal requirements may differ depending on culture and government, customers tended to prefer Web sites providing a maximum of technically guaranteed privacy protection (Steinke, 2002).

Knowledge of the consumer's characteristics, buying and consumption behavior provides the basis for approaching the consumer's private space in a personalized manner. Personalization has been defined (Peppers and Rogers, 1993) as a process in which the customer's information is used to supply solutions oriented towards that customer. Still, its meaning varies as the definitions given use often similar terms but in a different interpretation (Vesanen, 2007), leading to a more or less wrong understanding and making personalization employed rather on small-scale and merely for tactical applications.

The personalized consumer approach can not be separated from the drawbacks associated with the inappropriate administration and employment of the personal data (collected with or without the consumer's consent), due mainly to the insufficient knowledge of the consumers' personal information. As, on a hand, consumers often wants to exert control over the amount and nature of marketing information transmitted to them and, on the other hand, they will be eager to absorb only the information they have requested (Solomon, 2003), this knowledge becomes essential. As Godin (1999) suggested introducing the concept of permission-based marketing, this knowledge should be used having the consent of the consumer.

Increases in the amount of data to be collected, processed and used, new information and communication technologies employed to conduct all the related activities, necessity to protect the consumer rights having as background the context provided by the human rights have imposed public authorities to identify solutions to create and make work a proper legal environment of the personal data protection. Several generations of data protection norms have been built to ensure a better protection and the process continues (Jóri, 2007).

\section{Development of Data Protection in the European Union}

First laws regarding the protection of the personal data have been issued in Sweden - the Data Protection Act (1973) and United States - the Privacy Act (1974) and their implementation has been motivated mainly by the evolutions in the field of the public-owned data management (Stephens, 1998). In Europe, the first steps have been made through the European Convention for the Protection of Human Rights and Fundamental Freedoms (1950) that has defined the right to respect for private and family life (article 8). The Council of Europe has issued the Convention for the Protection of Individuals with regard to the Automatic Processing of the Personal Data (1981) defining the basic principles of the fair and lawful data collection and use. To implement the basic principles regarding the personal data protection, Council adopted several recommendations dealing with medical records (1981), scientific and other statistical research (1983), direct marketing (1985), social security (1986), police records (1987), employment data (1989), financial payments and related transactions (1990), communication of data to third parties by public institutions (1991), protection of personal data in the field of telecommunications, in particular telephone services (1995), protection of medical and genetic data (1997), protection of personal data collected and processed for statistical purposes (1997) and protection of privacy on the Internet (1999).

In this context, according to the European law, the content of privacy covers various aspects related to the protection of an individual's personal space that exceeds data protection, such as 
private, family and home life, physical and moral integrity, honor and reputation, avoidance of being placed in a false light, non-revelation of irrelevant and embarrassing facts, unauthorized publication of private photographs, protection against misuse of private communications, protection from disclosure of information given or received by the individual confidentially (Kuner, 2009).

European Convention and the OECD Guidelines on the protection of privacy and transborder flows of personal data, issued in 1980 and globally accepted later, have provided the background for the later issuing of the Directive 95/46/EC on the protection of individuals with regard to the processing of personal data and on the free movement of such data. All the Member States of the European Union have basically adopted and/or transposed its provisions. Directive has had a far greater global impact than thus far acknowledged becoming the main engine of an emerging global data protection regime being used as a non-coercive mechanism of soft legal globalization (Birnhack, 2008).

Bergkamp (2002) has observed that the Directive has not defined privacy and consequently created a troubling institutional framework in terms of the personal data protection. He has identified that solving the privacy issue implies the "classical choice of political philosophy" option between relying on the market, respectively on the government to produce and deliver privacy, suggesting that markets provide more flexibility and ability to accommodate the diverging demands while government creates laws imposing one-fits-all solutions focused merely on formal solving of the problem.

Analyzing the context of personal data protection development within the European Union based on this directive, Safell has found (2007) that European data protection law balances between rights of the data subjects and needs of data controllers, there are different approaches (statutory, administrative etc.) at national level in applying personal data protection law, and the Member States still play a large role in defining approach to data processing.

\section{Research Methodology and Main Findings}

Monitoring the perceptions, attitudes and views of the European Union's citizens on the data protection issues, has been a permanent concern of the European Commission since 1991. The main instrument employed in this respect has been the survey conducted at the level of a sample including respondents from all the Member States (more than 27,000 being interviewed in the latest survey conducted in 2008). Major topics approached in the most recent survey were the following:

- general feelings and concerns about data privacy;

- trust placed in different types of organizations holding personal data;

- awareness of the data protection rights and of the national protection authorities;

- perceived security of data transmission over the Internet and the employment of tools to improve the data security; and,

- attitudes on the restriction of the data protection rights in the light of international terrorism. In order to explore the views of the European citizens regarding the protection of their personal data, three types of data (collected in the latest survey conducted in January 2008 and published in February 2008) have been considered, corresponding to the same amount of major objectives of the research:

(1) the overall concern of the respondents regarding the holding of their personal data by the different organizations present in the market;

(2) awareness of the respondents in terms of the means and ways they may take into consideration and employ in protecting their personal data; and,

(3) perception associated by the consumers to the appropriateness (or, in other words, effectiveness) of the personal data protection in their home countries.

For the purpose of this research, the term "citizens" has been replaced, according to the context, with those of "consumers" and/or "respondents" as to extend the meaning of the data interpretations beyond the specialized area of the citizens' rights and to come closer to the field that 
is the most frequently associated and significantly affected by the consumers' views and expectations regarding their personal data protection - direct marketing.

\section{Main Findings of the Research}

Protection of the personal data appears, at the level of the European Union, to be a concern for the majority of the investigated respondents with almost two-thirds of them being very or fairly concerned about the ways the organizations keep and use their personal data. Data presented in the Figure no. 1 illustrate the significant differences between the EU Member States in terms of this aspect. Consumers from Malta (90\%), Austria (86\%), Germany (86\%), Lithuania (79 $\%)$, United Kingdom (77\%), and Sweden (76\%) seem to be the most concerned while consumers from the Netherlands (32\%), Bulgaria (34\%), Finland (36\%), Czech Republic (36\%), and Poland (42\%) appear to be the least concerned in this respect.

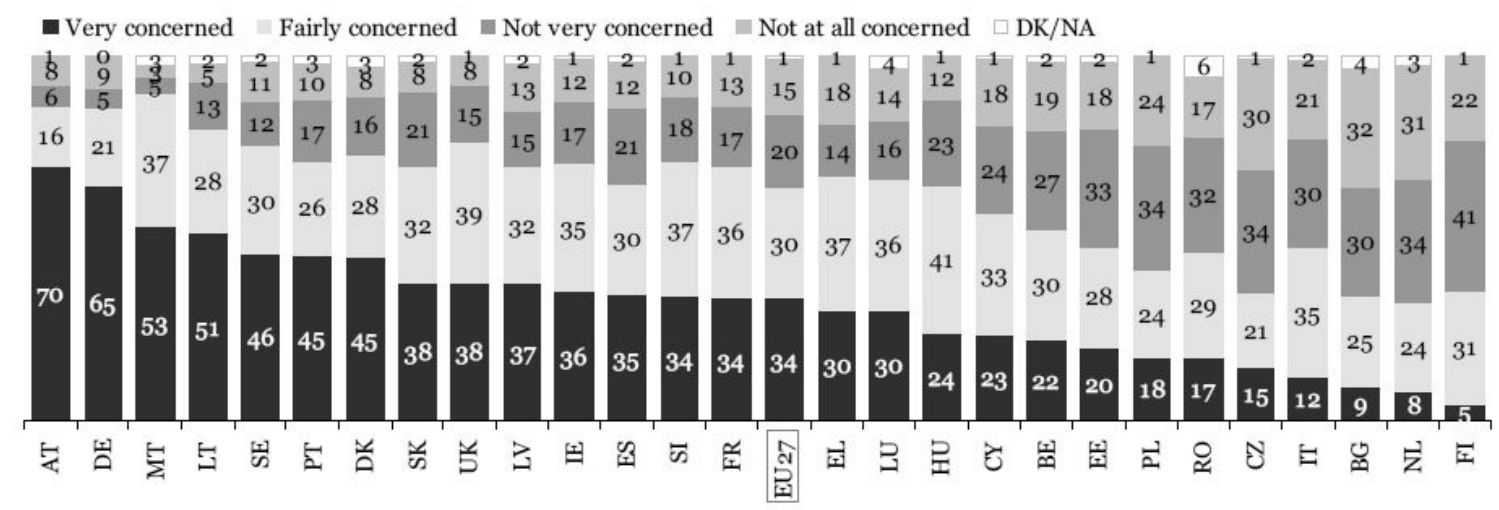

Fig. no. 1 - Concerns about personal data held by the organizations

(Source: Data Protection in the European Union. Citizens' Perceptions, Flash Eurobarometer No. $225, p .7)$

The level of concern appears to be higher in the older Member States by comparison to the New Member States. Thus, $65 \%$ of the consumers of the older Member States are very or fairly concerned about how the organizations handle their personal data, with Austria and Germany leading the hierarchy (both with percentages of $86 \%$ ), and with the Netherlands (32\%) and Finland (36\%) ending it. Consumers from the New Member States were very of fairly concerned in this respect at an average level of $56 \%$, these ten countries being split in two equal groups, one above the average including Lithuania (79\%), Slovenia (71\%), Slovakia (70\%), Latvia (69\%), and Hungary (65\%), and the other below the average, with Bulgaria (34\%), Czech Republic (36\%), Poland (42\%), Romania (46\%), and Estonia (48\%).

Differences between the 27 Member States could be explained, at least to a certain extent, by the overall development of the economies and markets as well as by the specific level of development of the direct marketing industry that is the main employer of the consumers' personal data. Still, some results, such as the presence of Malta and Lithuania in the top of the concern regarding the handling of the personal data of their citizens or the gap between the Czech Republic and Slovakia, may lead to the conclusion that there could be some cultural factors making the difference in this respect. 


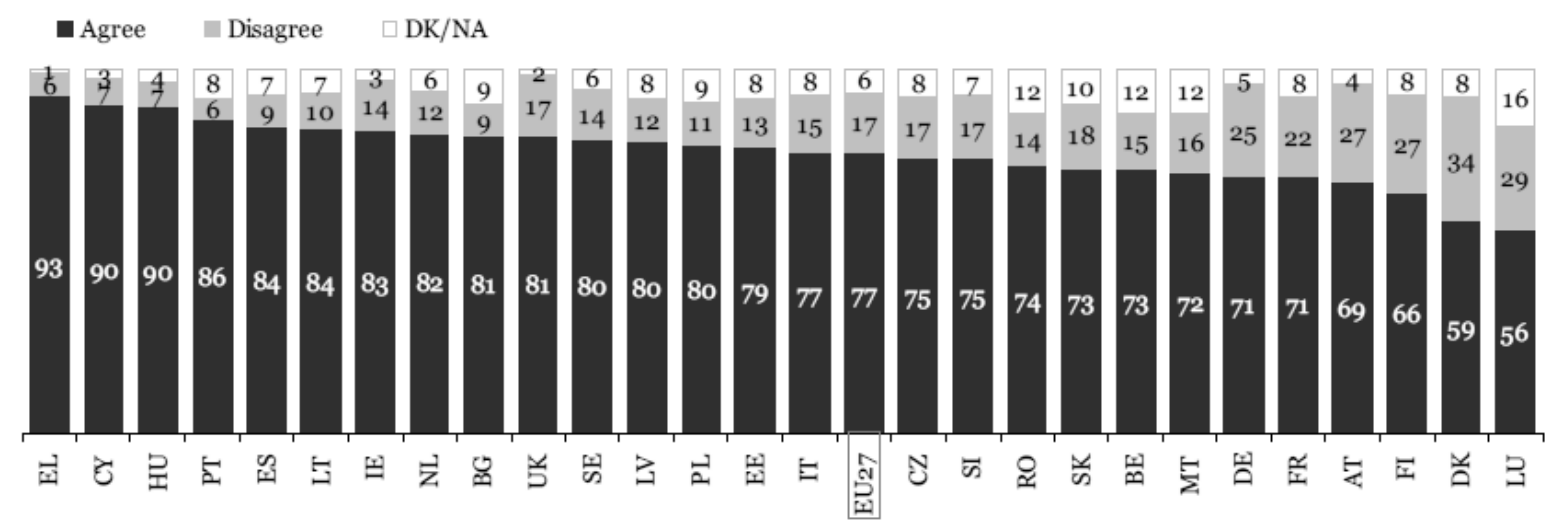

Fig. no. 2 - Awareness about the protection of the personal data (Source: Data Protection in the European Union. Citizens' Perceptions, Flash Eurobarometer No. 225, p.20)

Apparently, consumers from all the European Union's Member States are not aware about the means and ways they could employ to protect their personal data: $77 \%$ of all the investigated respondents have agreed that the degree of awareness of their co-nationals in terms of the personal data is low. Consumers from Greece (with a percentage of $93 \%$ ), Cyprus $(90 \%$ ) and Hungary (90 \%) seem to be the least aware while consumers from Luxemburg (56\%) and Denmark (59 \%) appear to have better, yet insufficient, knowledge in this respect.

Assessment of the European Union consumers' awareness regarding the level of protection of their personal data in their home countries conducted by calculating the difference between the percentages of the respondents that agree, respectively disagree that the level of protection of their personal data is low, confirms (through the determined result of -60) that the overall awareness is rather low. Consumers from Greece (with a result of -87), Hungary and Cyprus (both with -83), Portugal (-80), Spain (-75), and Lithuania (-74) are the least aware, while consumers from Denmark (-25), Luxembourg (-27), Finland (-39), Austria (-42), and Germany (-46) are aware to a larger extent although their knowledge should be improved in this respect.

The degree of awareness appears to be higher in the New Member States by comparison to the older Member States but the difference seems not significant. Thus, $79.1 \%$ of the citizens of the New Member States believe that awareness regarding the protection of their personal data in their home countries is low, with Hungary $(90 \%)$ and Lithuania $(84 \%)$ leading the hierarchy, and Slovakia (73 \%) and Romania (74 \%) ending it. Consumers from the older Member States were also very closed in assessing the awareness of their co-nationals in terms of the personal data protection, $75.4 \%$ of them considering as low the degree of awareness, with Greece (93\%), Portugal (86\%) and Spain (84\%) leading the hierarchy, respectively Luxembourg (56\%) and Denmark (59\%) being placed at its end.

The most important observation that can be made in this respect is that European Union's consumers need to improve their knowledge regarding the content of the personal data, the existing laws and regulations ensuring the protection of their personal data, and the rights they have and should exert in defending their privacy. The low awareness about the personal data protection means, ways and institutions that characterizes the majority of the respondents in all the 27 Member States, regardless the overall development of the home countries' economies and markets or the development of the direct marketing industry, suggests that they are exposed, basically to the same extent, to the potential threats related to the misuses of the personal data and, consequently, to the abuses against their privacy.

According to the majority of the investigated respondents $(48 \%)$, personal data are protected properly at the level of the European Union. Still, the relatively high percentage of the respondents disagreeing on this aspect and assessing this protection as inadequate (45\%), suggest that there is still more to be done in order to ensure an effective and satisfactory level of protection. 


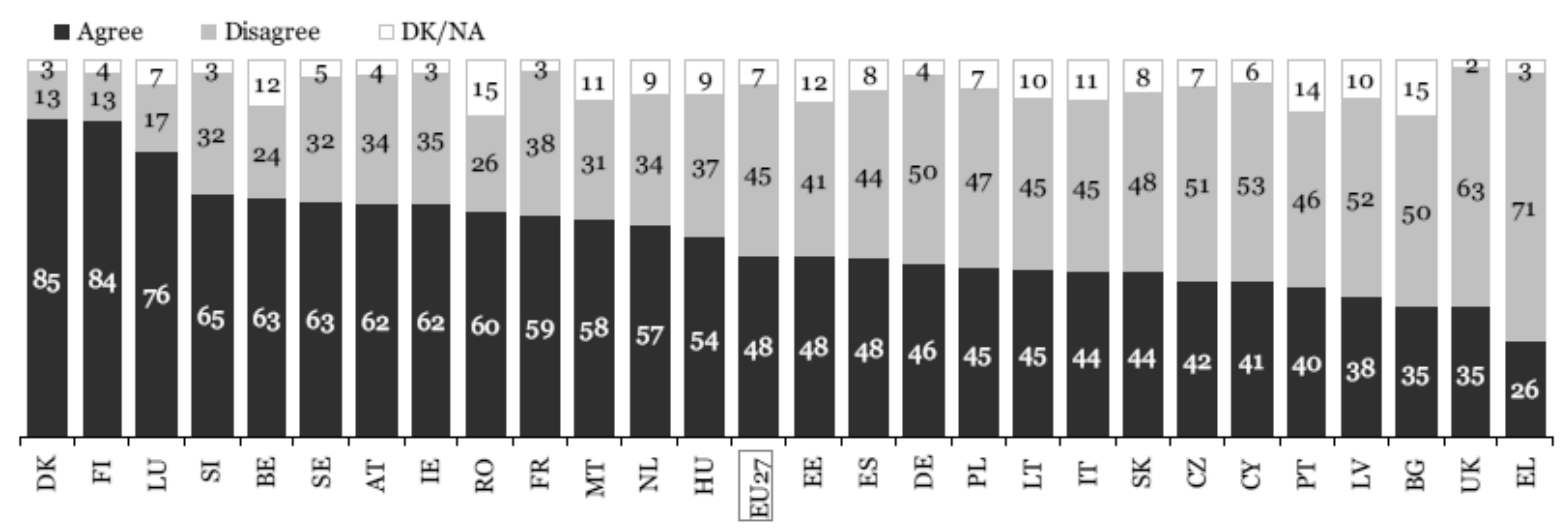

Fig. no. 3 - Views regarding the personal data protection in the European Union's countries (Source: Data Protection in the European Union. Citizens' Perceptions, Flash Eurobarometer No. 225, p.22)

There are significant differences between the all Member States in this respect, described by the gap between the percentages of $85 \%$ of the Danish respondents in Denmark, respectively to that of only $26 \%$ of the Greek respondents viewing the protection of personal data as properly ensured.

Assessment of the European consumers' view regarding the protection of their personal data in their home countries calculating the difference between the percentages of the respondents that agree, respectively disagree on how properly the protection of their personal data is provided, confirms (through the determined result of 3 ) that the overall level of protection is a rather moderate one. Consumers from Denmark (with a result of 72), Finland (71), and Luxembourg (59) are the most confident in the way their personal data are protected while consumers from the United Kingdom (-28) and Greece (-45) have the major reserves regarding the adequacy of their personal data protection in their home countries.

There is a significant difference between the older and the New Member States in terms of the adequacy of the personal data protection: although the overall opinion expresses a rather positive view on this aspect at the level of the both groups of states, the score (and, thus, the confidence in the properly done protection of the personal data in their home countries) appears to be higher in the older than in the new Member States (19.6, by comparison to only 4.7). Greece and United Kingdom are the countries where consumers demand a more appropriate protection of their personal data while Portugal $(-6)$, Germany $(-4)$, and Italy $(-1)$ have registered scores that may suggest not necessarily an improper protection of the personal data but rather a concern for defending the privacy and the consumer private space.

At the level of the New Member States, on the background given by the overall conclusion that protection of the personal data is rather properly ensured but further improvements should be expected, the differences between the countries are extremely interesting. Thus, consumers from Romania (34) and Slovenia (33) seem to be rather content about how their personal data are protected (but the reasons supporting this level of content could very diverse, from an effective content regarding the laws and their implementation to a potential lack of knowledge or of interest concerning the privacy and the protection of the personal data!), those from Hungary (17) and Estonia (9) are rather content but expect improvements while consumers from Poland (-2), Slovakia (-4), Czech Republic (-9), Latvia (-14), and Bulgaria (-15) are not satisfied with the current level of protection of their personal data.

The overall higher level of development of the economies, markets, the better experience of both the organizations in and of the consumers with the field of direct marketing, the existing laws and regulations regarding the data protection and, generally, the consumer rights are the main determinants of the differences between the older and the new Member States in this respect. 


\section{Conclusions}

Protection of the personal data appears, at the level of the European Union, to be a concern for the majority of the investigated respondents with almost two-thirds of them being very or fairly concerned about the ways the organizations keep and use their personal data. The level of concern appears to be higher in the older Member States by comparison to the New Member States.

Consumers from all the European Union's Member States seem to not be aware about the means and ways they could employ to protect their personal data, most part of them agreeing that the degree of awareness of their co-nationals in terms of the personal data is low. The degree of awareness appears to be higher in the New Member States by comparison to the older Member States but the difference seems not significant.

According to the majority of the investigated respondents, personal data are properly protected at the level of the European Union. Still, the relatively high percentage of the respondents weighting this protection as inadequate suggests that there is more to be done to ensure an effective protection. There is a significant difference between the older and the New Member States in terms of the adequacy of the personal data protection, the confidence in the properly done protection of the personal data appears to be higher in the older than in the new Member States.

Probably, the most important that can be drawn at the end of this exploratory assessment states that there significant difference between the all Member States of the European Union in terms of the views, worries and expectations regarding the protection of the consumers' personal data and privacy. The institutional concern to create a European legal framework, by issuing the Directive 95/46/EC and through the harmonization of all the provisions on the subject of data protection, has succeeded to build a relatively uniform legal reference. Still, the citizens (as well as the consumers) of the European Union member states seem to have different assessments and, consequently, expectations in terms of the protection of their personal data and privacy.

\section{References}

1. Bergkamp, L., 2002. EU Data Protection Policy. The Privacy Fallacy: Adverse Effects of Europe's Data Protection Policy In An Information-Driven Economy. Computer Law \& Security Report, Vol. 18, no. 1, pp. 31-47.

2. Birnhack, M. D., 2008. The EU Data Protection Directive: An Engine of a Global Regime. Computer Law \& Security Report, Vol. 24, pp. 508-520.

3. Godin, S., 1999. Permission Marketing: Turning Strangers Into Friends And Friends Into Customers. Simon \& Schuster, New York.

4. Grant, H., 2009. Data protection 1998-2008. Computer Law \& Security Report, Vol. 25, pp. 44-50.

5. Jóri, A., 2007. „Data Protection Law - An Introduction”. available online at http://www.dataprotection.eu/pmwiki/pmwiki.php?n=Main.Privacy.

6. Kemp, R., Moore, A. D., 2007. Privacy. Library Hi Tech, Vol. 25, No. 1, pp. 58-78.

7. Kuner, C., 2009. An International Legal Framework for Data Protection: Issues and Prospects. Computer Law \& Security Report, Vol. 25, pp. 307-317.

8. Peppers, D., Rogers, M., 1993. The One-to-One Future. Double Day, New York.

9. Safell, J., 2007. Personal Data Protection Law and Direct Marketing in the EU: Comparisons and Comments, presented at RoDirect 2007, Second International Direct Marketing Conference, Bucharest, 19-20 April 2007

10. Solomon, M. R., 2003. Conquering consumerspace: marketing strategies for a branded world. AMACOM, New York.

11. Solove, D. J., 2002. Conceptualizing privacy. California Law Review, Vol. 90, No. 4, pp. 1087-1155.

12. Stephens, D. O., 1998. Data Protection in Europe. ARMA Records Management Quarterly, Vol. 32, no. 4. 
13. Steinke, G., 2002. Data Privacy Approaches from US and EU Perspectives. Telematics and Informatics, Vol. 19, pp. 193-200.

14. Vesanen, J., 2007. What is personalization? A conceptual framework. European Journal of Marketing, Vol. 41, No. 5/6, pp. 409-418.

15. Westin, A., 1968. Privacy and Freedom, Athenaeum, New York.

16. $* * *$ - Data Protection in the European Union - Citizens' Perceptions. Analytical Report. Available online at http://ec.europa.eu/public_opinion/flash/fl_225_en.pdf. 